\title{
Anastomotic aortic leak: Still a challenging complication. Operate or look out the window?
}

\author{
Francesco Formica, MD, ${ }^{\mathrm{a}}$ Stefano D’Alessandro, MD, FECTS, ${ }^{\mathrm{a}}$ and Vittorio Maria Segramora, $\mathrm{MD}^{\mathrm{b}}$
}

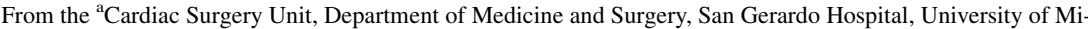
lano-Bicocca; and the ${ }^{\mathrm{b}}$ Vascular Surgery Unit, Cardiovascular and Thoracic Department, San Gerardo Hospital, Monza, Province of Monza and Brianza, Italy.

Disclosures: Authors have nothing to disclose with regard to commercial support.

Received for publication Sept 5, 2017; accepted for publication Sept 8, 2017; available ahead of print Sept 30, 2017.

Address for reprints: Francesco Formica, MD, Clinica Cardiochirurgica, Ospedale San Gerardo, Via G.B. Pergolesi 33, Monza 20052, Province of Monza and Brianza, Italy (E-mail: francesco_formica@ fastwebnet.it). J Thorac Cardiovasc Surg 2018;155:e11-2

$0022-5223 / \$ 36.00$

Copyright (c) 2017 by The American Association for Thoracic Surgery

https://doi.org/10.1016/j.jtcvs.2017.09.027
}

When we read the article in this issue of the Journal by Bouassida and coworkers, ${ }^{1}$ two therapeutic strategies came to our minds: first, the surgeon should perform a total aortic arch replacement operation; second, the surgeon should passively watch from the window and wait for a vascular surgeon for a conventional thoracic endovascular aortic repair.

Whatever the choice, distal aortic anastomotic leak after surgery for an acute type A aortic dissection (aTAAD) is challenging to treat and potentially fatal. Despite the improvement of surgical results of aTAAD, a large cohort of patients continues to have progressive aortic arch and descending aorta dilatation, mainly as a result of false lumen patency. ${ }^{2}$ The distal anastomotic leak determines the direct blood flow into the false lumen and further increase in the aortic diameter ${ }^{3}$ during the midterm follow-up, even after initially excellent results. ${ }^{4}$ Several factors. such as the patent false lumen, degeneration of the aortic wall, surgical procedure, poor surgical technique, infection, and Marfan syndrome may lead to aorta-related reoperations. ${ }^{5}$

Bouassida and coworkers ${ }^{1}$ treated a midterm distal anastomotic leak in a 65-year-old patient who had previously undergone an ascending aorta replacement by a supracoronary Dacron polyester fabric tube for an aTAAD. The distal anastomotic leak exclusion was obtained by using an Amplatzer Vascular Plug II (St Jude Medical, LLC, St Paul, Minn) delivered from the false lumen. The computed tomographic follow-up demonstrated false-lumen thrombosis at 1 year and aortic remodeling at 7 years. Few case reports have been reported in the literature so far. ${ }^{6,7}$ This represents the only case with a follow-up longer than 6 years.

The exclusion of distal anastomotic leak by the deployment of Amplatzer Vascular Plug II as an alternative to a thoracic endovascular aortic repair operation is the main strength of this case report, because conventional highrisk surgery is avoided and no prosthesis material is used. Bouassida and coworkers ${ }^{1}$ are to be commended for their result. Nevertheless, they did not mention the risk of device

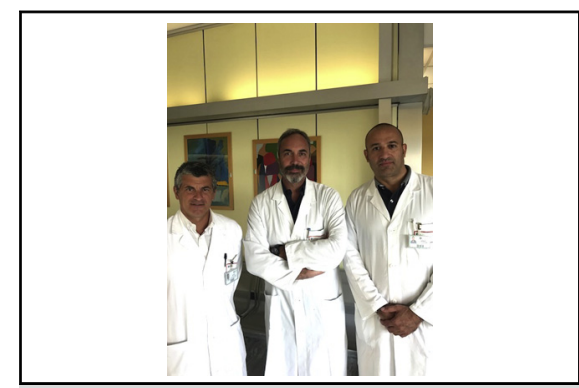

Left to right. Francesco Formica, MD, Vittorio Maria Segramora, MD, and Stefano D'Alessandro, MD, FECTS

\section{Central Message}

The technique reported in this issue of the Journal is a valid alternative to TEVAR in distal aortic anastomotic leak after surgery for an acute type A aortic dissection in high-risk patients.

See Article page e7.

failure during delivery, which may lead either to its failure to be occlusive or to the risk of distal migration and potential further dramatic complications. These risks are the main limitations of this procedure.

To prevent patency of aortic false lumen, it is worth considering a partial or total aortic arch replacement when surgical risks are acceptable, even to performing an elephant trunk technique. This can also facilitate a second-stage surgical repair or a thoracic endovascular aortic repair.

The new era of hybrid aortic prosthesis has opened up the possibility of definitively treating patients with aTAAD at the time of the first emergency operation and in cases of reoperative surgery for aortic arch replacement, such as frozen elephant trunk. This technique reduces the operating time and the rate of postoperative complications and makes the surgery definitive.

Although mortality after a conventional elephant trunk or frozen elephant trunk technique remains acceptable, ${ }^{8}$ in a center dedicated to aortic surgery, the option of treating anastomotic leak through an endovascular approach has to be taken into account, mainly in high-risk reoperative surgery. Despite some limitations, this technique is feasible and may provide a valid alternative to address this serious complication. At this point, the surgeon can be comfortable looking out the window. 


\section{References}

1. Bouassida I, Merygnac O, Marcheix B, Revel-Mouroz P, Rousseau H. Treatment of postoperative distal anastomotic endoleak with the Amplatzer Vascular Plug II in chronic aortic arch dissection: a case report. J Thorac Cardiovasc Surg. 2018; 155:e7-10.

2. Tanaka H, Okada K, Kawanishi Y, Matsumori M, Okita Y. Clinical significance of anastomotic leak in ascending aortic replacement for acute aortic dissection. Interact Cardiovasc Thorac Surg. 2009;9:209-12.

3. Leontyev S, Haag F, Davierwala PM, Lehmkuhl L, Borger MA, Etz CD, et al. Postoperative changes in the distal residual aorta after surgery for acute type A aortic dissection: impact of false lumen patency and size of descending aorta. Thorac Cardiovasc Surg. 2017;65:90-8.

4. Ghazy T, Mahlmann A, Fajfrova Z, Darwish A, Eraqi M, Hegelmann H, et al. Anastomotic leak after surgical repair type A aortic dissection- prevalence and consequences in midterm follow-up. Vasa. 2017;46: 377-82.

5. Concistrè G, Casali G, Santaniello E, Montalto A, Fiorani B, Dell'Aquila A, et al. Reoperation after surgical correction of acute type A aortic dissection: risk factor analysis. Ann Thorac Surg. 2012;93:450-5.

6. Pu J, Huang L, Wu W. Transcatheter closure of anastomotic leakage after aortic surgery for type A dissection with the Amplatzer Duct Occluder II. Cardiovasc Intervent Radiol. 2017;40:1274-7.

7. Yeom SK, Lee SH, Chung HH, Shin JS. Endovascular repair of growing chronic type B aortic dissection with a vascular plug. Acta Radiol. 2012; 53:648-51.

8. Shrestha M, Haverich A, Martens A. Total aortic arch replacement with the frozen elephant trunk procedure in acute DeBakey type I aortic dissections. Eur J Cardiothorac Surg. 2017;51(Suppl 1):i29-34. 